\title{
Educação Infantil e Pedagogia Histórico- Crítica: apontamentos sobre a educação escolar
}

\author{
Childhood Education and Historical-Critical Pedagogy: notes on School Education
}

Educación Infantil y pedagogía histórico-Crítica: apuntes sobre educación escolar

\author{
Fernanda Yully dos Santos Monteiro ${ }^{\mathrm{I}}$
}

\begin{abstract}
Resumo
O texto apresenta como objeto de reflexão a educação infantil e as teorias pedagógicas do "aprender a aprender" atreladas ao construtivismo e pós-modernismo, que fazem parte de um processo intencional de desescolarização das crianças de zero a cinco anos. Como método de elaboração do conhecimento, utilizase o materialismo histórico dialético e a pedagogia histórico-crítica como arcabouço teórico/metodológico que permite compreender a essência do objeto. Enquanto resultados da pesquisa aponta-se que a pedagogia histórico-crítica é uma teoria do conhecimento contra-hegemônica que pode balizar o ensino da educação infantil, uma teoria que busca ascender e superar o senso comum através da apropriação do conhecimento elaborado na escola.
\end{abstract}

Palavras-chave: Educação Infantil; Pedagogia Histórico Crítica; Educação Escolar

\begin{abstract}
The text presents as object of reflection the early childhood education and the pedagogical theories of "learning to learn" linked to the constructivism and postmodernism, which are part of an intentional process of unschooling children from zero to five years old. As a method of elaboration of knowledge, dialectical historical materialism and historical-critical pedagogy are used as the theoretical / methodological framework that allows understanding the essence of the object. As a result of the research, it is pointed out that the historical-critical pedagogy is a counter-hegemonic theory of knowledge that can guide the teaching of early childhood education, a theory that seeks to rise and overcome common sense through the appropriation of knowledge elaborated in school.
\end{abstract}

Keywords: Childhood Education; Historical-Critical Pedagogy; Schooling

${ }^{\text {I } U n i v e r s i d a d e ~ F e d e r a l ~ d o ~ P a r a ́ ~-~ U F P A ~-~ R . ~ A u g u s t o ~ C o r r e ̂ a, ~} 01$ - Guamá, Belém - PA, 66075-110 - fernmonteiro1301@gmail.com 


\section{Resumen}

El texto presenta como objeto de reflexión la educación infantil y las teorías pedagógicas de "aprender a aprender" vinculadas al constructivismo y al posmodernismo, que forman parte de un proceso intencional de desescolarización de niños de cero a cinco años. Como método de elaboración del conocimiento, se utiliza el materialismo histórico dialéctico y la pedagogía histórico-crítica como marco teórico/metodológico que permite comprender la esencia del objeto. Como resultado de la investigación señalase que la pedagogía histórico-crítica es una teoría del conocimiento contra hegemónica que puede guiar la enseñanza de la educación de la primera infancia, una teoría que busca eclodir y superar sentido común a través de la apropiación del conocimiento más elaborado en la escuela.

Palabras clave: Educación Infantil; Pedagogía Histórico-Crítica; Educación escolar

\section{Introdução}

O texto em tela é um recorte da dissertação de mestrado apresentada ao Programa de Pós-Graduação em Educação da Universidade Federal do Pará. Apresenta-se no intuito de discutir a educação escolar, mais especificamente a primeira etapa da educação básica, a educação infantil. Trata-se de um estudo teórico acerca de um ensino que supere o espontaneísmo na educação infantil. Para tal, sugere-se que as bases teóricas que pautam o ensino das crianças de zero a cinco anos sejam críticas e comprometidas com um ensino omnilateral ${ }^{1}$ do educando.

O cuidado com a infância surge na perspectiva de "propiciar espaços para que as famílias trabalhadoras pudessem deixar seus filhos supostamente protegidos e cuidados em suas necessidades fundamentais, biológicas, psicológicas e sociais, liberando pais e mães para o trabalho" (LOMBARDI, 2013 p.10).

Destarte, os espaços para a educação infantil surgem da própria lógica do capital, que ao necessitar da mão de obra dos pais e mães que pertencem à classe trabalhadora, organiza uma estrutura para receber as crianças no tempo de trabalho de seus familiares e cuidadores. Dito isso, é fundamental compreender que o ensino das crianças menores de seis anos sempre esteve atrelado ao viés do cuidado em detrimento da educação, ou mesmo em oposição ao ensino.

A gênese da educação infantil apresenta diferenças em relação aos demais níveis de ensino. Enquanto a escola contemporânea tem suas bases demarcadas pelos ideais do iluminismo e da revolução

\footnotetext{
${ }^{1}$ Para Manacorda (2011), a omnilateralidade pode ser compreendida enquanto a defesa de uma formação que integra ciência e técnica ao desenvolvimento do homem em todas as suas potencialidades, superando contradições e antagonismos de classe. Ainda segundo o autor, a omnilateralidade é um conceito de viés marxista, que aponta a união entre ensino e trabalho, evocado pelo projeto jacobino Lepeletier que propunha uma educação "literária, intelectual, física, moral e industrial”(MANACORDA, 2011 p. 7). Nesse sentido, a educação omnilateral está alicerçada em uma tríplice formação que permite o pleno desenvolvimento do ser humano, a primeira trata-se da formação intelectual, a segunda da educação física e a terceira do ensino politécnico.
} 
francesa $^{2}$, a educação infantil surge envolta em um caráter assistencialista, que objetivava retirar as crianças pequenas de ambientes passíveis de contaminá-las. Esteve atrelada, portanto, a um caráter higienista. Em contrapartida ao avanço que representava a inserção da educação infantil dentro da escola, a educação oferecida apresentava baixa qualidade, e era distante da ideia de emancipação (STEMMER, 2012).

Desse modo, enquanto a escola surge com caráter formador, a educação infantil não está relacionada a tais ideais, nasce por urgência assistencialista e para suprir uma necessidade do modelo produtivo que introduzia nova funcionalidade ao papel social feminino: o trabalho. Logo, alguém teria que se ocupar das crianças no período em que as mães estivessem exercendo seus deveres. As creches e pré-escolas tornamse espaço para isso, não apresentando o mesmo caráter formativo das escolas que cuidavam dos demais níveis de ensino.

No que tange a formação de professores da Educação Infantil, no Brasil, Campos, Füllgraf e Wiggers (2006) demarcam que somente a partir da reformulação na legislação - constituição federal de 1988 e LDB de 1996 - surge a exigência de formação superior para professores e educadores ${ }^{3}$ da educação infantil. Entretanto, o curso de magistério em nível médio ainda era admitido. Assim, foram organizados cursos de formação para os educadores leigos. As autoras ainda apresentam um dado crítico indicativo de falta de atendimento à determinação legislativa em que muitas prefeituras e entidades, violavam a imposição da formação de professores buscando subterfúgios como "contratando educadores como se desempenhassem atividades de limpeza, para fugir ao requisito de formação prévia" (CAMPOS; FÜLLGRAF; WIGGERS, 2006, p. 90).

Assim, fica explicito que o surgimento do ensino das crianças da educação infantil não esteve ligado à perspectiva de inserção ao mundo da cultura, sendo secundários aspectos como: a formação dos professores que atuavam neste nível de ensino, o que repercute na atualidade sobre o ensino, didática e organização do trabalho pedagógico das crianças de 0-5 (zero a cinco) anos de idade.

A partir dessa breve exposição do histórico da educação infantil, aponta-se a necessidade da prática pedagógica do professor e a organização do trabalho Pedagógico na educação infantil atrelado a teorias críticas que possibilitem o desenvolvimento omnilateral do sujeito.

\footnotetext{
${ }^{2} \mathrm{~A}$ escola contemporânea tem suas bases atreladas aos ideais iluministas e a revolução francesa. Os sistemas educacionais, por sua vez, consolidaram-se apenas no século XIX (STEMMER, 2012 p.6). "A escola pública teve sua amplitude limitada até o último terço da do século XIX. Esse fenômeno foi geral. Só a França realizou um debate perceptível e, por isso, foi a mais prolífera do ponto de vista da produção teórica acerca da temática educacional" ( ALVES, 2006 p.118). Fora da França, as discussões acerca da educação e instrução pública de maneira geral tinham um peso político menor, estando subordinada as demais questões que faziam parte da sociedade de maneira global, destaca-se a importância do século XIX para a expansão escolar e dos sistemas de ensino.

${ }^{3}$ As autoras utilizam nomenclaturas diferentes para aqueles que possuíam alguma instrução voltada ao ensino escolar, ou seja, caracterizam como professores aqueles que obtinham formação a nível de magistério, o que infere grau de profissionalização e caracteriza enquanto educadores os profissionais considerados leigos que não obtinham formação mas desempenhavam igual função.
} 
O cenário apresentado na atualidade aponta que a educação infantil assume grande influência de concepções educacionais calcadas no lema "aprender a aprender" e outras vertentes que têm contribuído para o esvaziamento dos conteúdos das aulas, fortalecendo uma visão hegemônica, a serviço do capital. Arce (2004), Duarte (2011) e Malanchen (2016) apontam que o construtivismo e opós-modernismo carregam consigo ideais do lema supracitado, isso implica em posicionamentos valorativos ${ }^{4}$ que atingem diretamente a educação escolar.

Malanchen (2016 p.68) ressalta que para os intelectuais que estão atrelados a vertentes "pós", a subjetividade, a experiência pessoal e a compreensão própria das experiências é que alicerçam o conhecimento, o que torna a realidade "incognoscível, isto é, a realidade é somente o que cada um percebe. O lema do "aprender a aprender" traz como princípio a premissa de que "o que se aprende por si mesmo é superior, em termos educativos e sociais, àquilo que se aprende através da transmissão por outras pessoas" (DUARTE, 2011 p.41-42). Desconsidera-se, nesse sentido, o mundo da cultura e o papel do professor no processo educativo e na aquisição de conhecimentos socialmente produzidos.

A partir da discussão em tela, este escrito busca colaborar através da pedagogia histórico-crítica enquanto contribuição contra-hegemônicano ensino da educação infantil.

\section{0 método de elaboração do conhecimento}

Trata-se de uma pesquisa explicativa alicerçada no materialismo-histórico dialético como método de elaboração do conhecimento e na pedagogia histórico-crítica enquanto teoria crítica da educação. A pesquisa explicativa é para Gil (2008) aquela que se preocupa em identificar fatores que determinam ou contribuem para a ocorrência dos fenômenos, é o tipo de pesquisa que mais aprofunda o conhecimento da realidade, porque explica a razão das coisas.

Segundo Paulo Netto (2011), o método de Marx é uma longa elaboração teórica. A teoria é, para Marx, a reprodução ideal do movimento real do objeto pelo sujeito que pesquisa. Pela teoria, o sujeito

\footnotetext{
${ }^{4}$ Os posicionamentos valorativos do lema "aprender a aprender" presentes no construtivismo e nas vertentes pós-modernas indicam que: 1) os indivíduos realizam aprendizagens por si mesmo, ou seja, há ausência de transmissão por outros indivíduos de conhecimentos e experiências. Desse modo, aprender sozinho seria algo que contribuiria com o desenvolvimento da autonomia do indivíduo e o contrário seria um obstáculo à produção desta autonomia; 2) o segundo posicionamento valorativo trata-se da ideia de que é mais importante o aluno desenvolver um método de aquisição, elaboração, descoberta, construção de conhecimentos, do que aprender o conhecimento que já foi descoberto e elaborado por outras pessoas; 3) Enquanto terceiro posicionamento valorativo, indica-se que para a atividade ser verdadeiramente educativa, deve ser impulsionada e dirigida pelo interesse e necessidades da própria criança; 4) Por fim, o quarto posicionamento valorativo contido no lema "aprender a aprender" aponta que a educação deve preparar os indivíduos para acompanhar uma sociedade em processo acelerado de mudança e estas transformações implicam em um conhecimento cada vez mais provisórios que é superado em poucos anos ou mesmo em meses (DUARTE, 2011).
} 
reproduz em seu pensamento a estrutura e a dinâmica do objeto pesquisado. Essa reprodução (que constitui propriamente o conhecimento teórico) "será tanto mais correta e verdadeira quanto mais fiel o sujeito for ao objeto" (PAULO NETTO, 2011 p. 20-21).

Em relação à pedagogia histórico-crítica, cumpre dizer que enquanto tendência pedagógica encontra-se no bojo das concepções críticas. Saviani (2013) caracteriza-a como uma teoria pedagógica que busca ser crítica sem ser reprodutivista.

Para apreensão da pedagogia histórico-crítica enquanto uma pedagogia transformadora, aponta-se que esta: 1) apresenta diretrizes pedagógicas; 2) apresenta finalidades e objetivos para a educação; 3) pensa sobre os conteúdos curriculares e os procedimentos didáticos do processo formativo.

Com base nos pressupostos da pedagogia histórico-crítica, a aprendizagem ocorre "do concreto para o abstrato, dos conceitos espontâneos para os científicos, da síncrese para a síntese pela mediação da análise" (MARTINS, 2016 p.72). O ensino orienta-se do abstrato para o concreto, utilizando os conceitos científicos como possibilidade de complexificação, o que possibilita aos destinatários a conquista do autodomínio da conduta, o pensamento por conceitos, a capacidade imaginativa, os sentimentos e valores éticos e estético, que são considerados atributos representativos do máximo desenvolvimento do gênero humano (MARTINS, 2016).

A escola faz parte da tarefa humanizadora que a pedagogia histórico-crítica defende, pois valida a transmissão dos conhecimentos historicamente sistematizados e referendado ao longo dos tempos conhecimentos clássicos -, orientada por um planejamento intencional e uma sistematização lógica dos conteúdos de ensino, articulando as melhores formas para sua transmissão, tudo isso calcado na tríade conteúdo- forma- destinatário (MARTINS, 2016).

Podemos considerá-la enquanto uma teoria que procura compreender a educação a partir de análises concretas da realidade, superando o que é apresentado através de métodos e princípios que estão atrelados ao desenvolvimento de processos pedagógicos (SAVIANI, 2013b).

A pedagogia histórico-crítica apresenta-se, desse modo, enquanto possibilidade concreta para a educação escolar, uma teoria pedagógica de base socialista que busca superar a naturalização do desenvolvimento humano, apresentando a escola e o conhecimento mais elaborado como forma de superar o senso comum e levar o homem ao seu máximo processo de desenvolvimento.

Ao tratar da periodização do desenvolvimento infantil, Pasqualini (2009) diferencia as funções psicológicas em elementares (comuns a homens e animais) e funções psicológicas superiores (exclusivamente humanas, tais como atenção voluntária, memória mediada e pensamento abstrato). As 
funções psicológicas superiores têm gênese fundamentalmente cultural, e superam as funções psicológicas elementares, com isso, as formas inferiores não se aniquilam, mas continuam existindo como instância subordinada às funções superiores. Assim, “poderíamos dizer que os processos elementares e as leis que os regem estão enterradas na forma superior do comportamento, isto é, aparecem nela subordinadas e ocultas" (PASQUALINI, 2009 p.34).

Destarte, pode-se afirmar que o desenvolvimento psíquico é um processo que se caracteriza por mudanças qualitativas, não é uma mudança de grau, do menos para o mais, mas uma mudança de tipo, uma mudança na qualidade da relação da criança com o mundo, que depende das mediações que serão oportunizadas e das oportunidades de apropriação da cultura humana que serão ou não garantidas (PASQUALINI, 2013).

Ou seja, pode-se inferir que o desenvolvimento da criança é um processo diretamente ligado a disponibilização dos bens materiais, espirituais e culturais produzidos pela humanidade. Assim, a pedagogia histórico-crítica como tendência da educação que busca disponibilizar o conhecimento mais desenvolvido, tem papel fundamental no processo de desenvolvimento infantil.

\section{Críticas ao "aprender a aprender" e a "liberdade" da criança na educação infantil}

Ao discutir-se a respeito da educação infantil, é possível constatar que dentro desta etapa de ensino as orientações pedagógicas hegemonizadas são teorias construtivistas com princípios centrados no lúdico e na "liberdade" da criança. Analisando tal perspectiva Bernardo e Pina (2013, p. 301) afirmam que "a prática pedagógica na educação infantil nega o direito da criança de se apropriar dos conhecimentos historicamente acumulados pela humanidade".

O ideário de liberdade difundido pela perspectiva construtivista aponta que o ensino da educação infantil necessita de autonomia e liberdade para a criança construir seu conhecimento, subjugando os conteúdos e a prática do professor.

Assim, Rossler (2004) aponta que o debate educacional contemporâneo tem em seu discurso um pano de fundo que cerca a seguinte problemática: "respeitar o universo da criança, seu cotidiano imediato, e, assim, ensinar o que ela já conhece ou tem condições imediatas de aprender, conforme seu grau de desenvolvimento" (p.76). E, é dentro desta perspectiva que o ensino das crianças da educação infantil limita suas vivências dentro do universo cotidiano, interesses e motivações das crianças.

Contrapondo esse panorama, Rossler (2004, p.76) aponta que: 
[...] a aprendizagem gera desenvolvimento e a formação do individuo não pode pautar-se naquilo que ele carrega de seu cotidiano imediato, posto que a vida cotidiana dos homens hoje, no interior da sociedade capitalista contemporânea, é uma vida essencialmente alienada.

Dito isso, compreende-se que a educação em qualquer nível de ensino não deve ter enquanto referência o que já se conhece, ou seja, o conhecimento cotidiano, do senso comum, seu conhecimento deve partir dos conteúdos socialmente úteis que elevem o nível de consciência dos indivíduos, instrumentalizando e humanizando os homens e mulheres que tiverem acesso a esse conhecimento.

Ainda acerca da "liberdade" da criança, é preciso debater que tipo de liberdade é essa. A partir de que critérios os professores e demais envolvidos no processo de ensino caracterizam a "liberdade" da criança dentro da escola? Assim, uma questão relevante se faz necessária: qual a concepção de "liberdade" difundida pelos ideais construtivistas?

Os ideais construtivistas têm baseado a ideia de liberdade da criança em um processo espontâneo do conhecimento, no qual cada criança dentro de seu processo formativo pode apontar que conhecimentos vivenciar e como fazê-lo, seria então a criança o centro do processo educativo, em oposição ao professor, a escola e aos conteúdos disponibilizados na educação escolar.

Rompendo essa ideia, concordamos com Saviani e Duarte (2012), que o ato educativo contribui de maneira singular para a liberdade da criança, não sendo este ato um processo espontâneo, pois a criança sempre partiria do senso comum e de suas atividades cotidianas.

Cumpre dizer que o ato educativo permite a passagem do senso comum a uma consciência filosófica ${ }^{5}$, e a liberdade trata desta inserção no mundo da cultura, para adquirir a liberdade é preciso ultrapassar o senso comum, por esse motivo a educação escolar é tão importante no processo educativo das crianças da educação infantil.

Para Saviani e Duarte (2012 p.14), o trabalho educativo "é o ato de produzir, direta e intencionalmente, em cada individuo singular, a humanidade que é produzida histórica e coletivamente pelo

${ }^{5}$ Para Saviani (2013a), toda educação deve ter uma orientação filosófica. Cumpre dizer que cada ser humano descobre sua existência no mundo através do agir, pensar, sentir; tal existência acontece no primeiro momento de forma espontânea, até que algo interrompe o seu curso, alterando essa sequência natural e obrigando o homem a examinar, procurar e descobrir o que é esse algo, é a partir desse momento que ele começa a filosofar, é certo que os problemas enfrentados pelo homem no transcurso de sua existência é que o levam a filosofar. A reflexão filosófica, no entanto, requer algumas exigências que podem ser resumidas em três requisitos: radicalidade, rigor e globalidade. Saviani (2013a) expõe que a radicalidade trata da necessidade de ir a raiz da questão, até seus fundamentos, exigindo que se opere uma reflexão profunda; o rigor garante a primeira exigência, colocando em questão as conclusões do senso comum e generalizações apressadas que a ciência pode ensejar e a globalidade trata da inserção do problema em um contexto, examinando sua função. Ou seja, pode-se inferir que a consciência filosófica é uma passagem do senso comum a um conhecimento mais elaborado, parte de problemas e reflexões sobre estes problemas, de forma profunda, organizada e que permita ações sobre a realidade apresentada. 
conjunto dos homens", ou seja, significa apresentar ao indivíduo o mundo da cultura, permitir-lhes a apropriação e superação por incorporação do senso comum, através do conhecimento apresentado na escola.

Assim, consideramos que a liberdade da criança só pode ser alcançada em sua totalidade a partir do momento que ela se depara com o mundo da cultura, e depois de apropriar-se daquilo produzido ao longo da história pelo gênero humano pode fazer suas próprias catarses, incorporando e superando aquilo que foi transmitido. Nesse momento, ao sair de um estado sincrético e apropriar-se de conceitos, a criança começa a superar o senso comum para ascender a uma consciência filosófica.

Esclarecer a questão da liberdade é fundamental, pois interfere diretamente no processo de ensino e na função que o professor exerce. Segundo Martins Filho (2008), a educação infantil apresenta o estigma de que "o professor neste nível de educação, não ensina, apenas orienta, observa, estimula e partilha relações”. Esse discurso de escolarização na educação infantil evidencia que há a negação do ato de ensinar. Dessa forma, "o conhecimento é considerado como algo produzido na e pela prática simplesmente, a figura do professor é colocada em segundo plano e a desqualificação da escola enquanto lugar de sistematização de conteúdos a serem transmitidos" (MARTINS FILHO, 2008).

Consideramos, portanto, que os ideais construtivistas balizados no "aprender a aprender" difundem uma visão de liberdade do senso comum. Heller apud Rossler (2004), ao tratar dessa questão, ressalta que o discurso contemporâneo das teorias educacionais aponta:

[...] o imediato em detrimento do mediato; o lúdico em detrimento do intelectual; o aprender (sozinho) em detrimento do ensino e do estudo sistemático; o pragmático em detrimento do teórico; a utilidade em detrimento da erudição; o fazer em detrimento do saber; o método em detrimento do conteúdo; o particular em detrimento do universal; o cotidiano em detrimento do não cotidiano (p.77).

O arcabouço ideológico dos discursos construtivistas tem íntima relação com as relações sociais de dominação, a escolarização proposta recai sobre uma pseudo liberdade difundida por esses ideais. Ou seja:

[...] esse mesmo discurso que possui caráter fortemente retórico e sedutor, que lhe transmite ares de uma teoria e de uma prática crítica, inovadora e transformadora, supostamente afinada com as necessidades naturais, biológicas, psicológicas dos seres humanos (ROSSLER, 2004, p.77).

Assim, encontram indivíduos dispostos a difundir tais ideais, de um discurso sedutor que parece ser progressista, mas não passa de armadilha àqueles que de fato pesam em uma educação transformadora.

Importante frisar que não há divergência em relação à construção da liberdade e autonomia da criança dentro do processo educativo, a discordância ocorre do ponto de vista do método e forma que ocorre 
o processo de difusão dessa 'liberdade'. Quando as teorias construtivistas se apropriam do slogan da 'liberdade da criança da educação infantil', introduzem ao processo uma construção unilateral que dar-seá da criança para o mundo, sem interferência do professor, o que por sua vez descaracteriza o ato educativo e a construção de qualquer liberdade e autonomia.

\section{Pedagogia Histórica-Crítica e Educação Infantil: uma teoria contra-hegemônica na educação escolar}

A pedagogia Histórico-Crítica é apresentada por Saviani (2013) como:

[...] uma teoria que procura compreender os limites da educação vigente e, ao mesmo tempo, superálos por meio da formulação de princípios, métodos e procedimentos práticos ligados tanto à organização do sistema de ensino quanto ao desenvolvimento dos processos pedagógicos que põem em movimento a relação professor-aluno no interior das escolas (SAVIANI, 2013, p. 119).

Essa teoria propõe uma perspectiva historicizadora dos conteúdos, ou seja, é definida pelo processo histórico (SAVIANI, 2013b), guiando-se pelo conceito de trabalho, possui um posicionamento e compromisso com um projeto histórico contra-hegemônico, uma concepção de homem e de mundo.

Saviani (2013b) apresenta os momentos pedagógicos da Pedagogia histórico-crítica como alternativa para superação da pedagogia nova e tradicional, afirmando que o ponto de partida do processo educativo parte da diferença de conhecimento entre os sujeitos (professor e aluno) referente ao conhecimento e experiência, que condiciona os alunos a um estado sincrético de conhecimento.

Lavoura (2018) adverte que o método da pedagogia histórico-crítica é dialético, operando com as categorias da contradição e ação recíproca e não por formalismos lógicos ou esquematizados. Desse modo, não se trata de uma relação mecânica entre os passos do método, mas momentos pedagógicos que se imbricam e que devem ser efetivados pelos professores com base no método dialético e não em uma estrutura didática única.

Quando se fala nas possíveis aplicações da Pedagogia Histórico-Crítica no campo educacional é com certa dúvida que se afirma sua possibilidade para o campo da Educação de crianças menores de seis anos. Dúvida alimentada pela imagem vulgarizada de que esta dita Pedagogia seria tradicional.

Nesse sentido, a pedagogia histórico-crítica é compreendida por alguns como uma pedagogia baseada na memorização, no ensino livresco, algo quase medieval. Portanto, para crianças pequenas a pedagogia histórico-Crítica estaria associada à tortura, deixando a criança de ser criança e de ser feliz. Nada mais pode representar esse tipo de afirmação do que o desconhecimento total a respeito do que seria a 
Pedagogia histórico-Crítica, e mesmo de quais são as possibilidades para o trabalho pedagógico na Educação Infantil (ARCE, 2013, p.5).

Contudo, esse duvidar tem seu mérito, pois as políticas públicas para a educação de crianças pequenas, bem como a produção hegemônica na área apontam para qualquer tentativa de intervenção intencional, direta por parte do adulto no desenvolvimento infantil como quase um verdadeiro sacrilégio, algo que feriria a alma infantil (ARCE, 2003).

Dentro desse contexto marcado pelo discurso que defende a desescolarização da Educação Infantil, trazer uma pedagogia que discute as possibilidades do "ensinar" e do "dirigir" intencionalmente o desenvolvimento infantil só poderia gerar dúvidas e desconfianças (ARCE, 2003).

A autora aponta o equívoco em relação a esse pensamento, que faz parte do discurso que se vincula ao não ensino na Educação Infantil. Ao avaliar a questão da desescolarização, é importante compreender que ela ocorre em todos os níveis de ensino. Na educação infantil, o ensino é secundarizado em relação à "liberdade da criança" e demais facetas que advém dos ideários que permeiam as pedagogias do "aprender a aprender", seguindo o processo na educação básica sobre o viés do sujeito polivalente ${ }^{6}$, que parte dos mesmos ideários que tem atingido a educação infantil, o construtivismo e o pós-modernismo.

Duarte (2011, p.106) demarca que o construtivismo e o pós-modernismo apresentam interfaces, tornando-se "quase a mesma coisa falar em construtivismo e pensamento educacional pós-moderno". Ambas as tendências estão ancoradas ao pensamento neoliberal e sua aproximação pode ser identificada pela ausência de diferenciação entre as características do pensamento não cotidiano (ciência, filosofia, política e arte) e do pensamento cotidiano (DUARTE, 2011).

Consideramos que o discurso das pedagogias construtivistas e pós-modernos, além de atrelados as demandas neoliberais, estão em conformidade com a desescolarização na educação infantil em um processo intencional de não acesso ao mundo da cultura, que devemos combater.

Destarte, aponta-se que a pedagogia histórico-crítica enquanto teoria pedagógica que tem suas bases alicerçadas pelo materialismo histórico-dialético e que defende o processo de escolarização é uma teoria contra- hegemônica de valor para o ensino das crianças desde a mais tenra idade.

${ }^{6} \mathrm{O}$ termo polivalência, por sua vez, tem sido comumente usado no contexto do mundo do trabalho, requisitado pelo discurso neoliberal no período pós-crise do capitalismo. Designa a capacidade de o trabalhador poder atuar em diversas áreas, podendo caracterizar ainda um profissional pautado pela flexibilização funcional. (CRUZ; BATISTA NETO, 2012). 


\section{Considerações provisórias}

O escrito apresentado realiza algumas considerações acerca das teorias pedagógicas na educação infantil e suas vinculações ao que consideramos uma falsa liberdade das crianças de zero a cinco anos dentro do ambiente escolar.

Consideramos a temática polêmica e como parte de nossa opção ética e política vinculamos o estudo à pedagogia histórico-crítica, entendendo-a como uma teoria pedagógica contra-hegemônica e atrelada a defesa de uma educação democrática. Destarte, consideramos que a pedagogia histórico-crítica permite desenvolver as funções psíquicas, incorporando as funções elementares às superiores, o que permite novas apropriações sobre o conhecimento socialmente produzido.

As teorias construtivistas e pós-modernas são hegemônicas no contexto da educação infantil e apresentam um conceito de liberdade desvinculado da escolarização tão importante na mais tenra idade.

Portanto, o texto busca contribuir com a desvinculação do ensino da educação infantil como um momento de liberdade espontânea, discutindo-a enquanto parte do mundo da cultura, no qual quanto mais acesso ao conhecimento as crianças possam ter mais livres possam ser enquanto sujeitos históricos.

Desse modo, avaliamos que este texto apresenta uma proposta em relação à teoria pedagógica crítica no ensino da educação infantil. Analisando, ainda, que a sistematização de conteúdos e organização do trabalho pedagógico nesta etapa da educação básica não é apenas pertinente, mas necessária, e a educação escolar formal é um direito de todas as crianças, de todas as idades.

Por fim, defendemos que toda sistematização de conhecimento deve apresentar diretriz pedagógica, finalidades e objetivos em relação a seus conteúdos e procedimentos didáticos que balizem o ensino. Destaca-se, neste contexto, que a pedagogia histórico-crítica enquanto teoria pedagógica vem demonstrando-se avançada, crítica, e de valor para a educação escolar, uma vez que apoia-se na transmissão do saber mais desenvolvido como forma de superar o conhecimento tácito.

\section{Referências}

ALVES, G. L. A produção da escola pública contemporânea. 4. Ed. Campinas, SP: Autores Associados, 2006.

ARCE, A. É possível falar em pedagogia histórico crítica para pensarmos a educação infantil?.Germinal: Marxismo e Educação em Debate, Salvador, v. 5, n. 2, p. 5-12, dez. 2013. 
BERNARDO, L.A.; PINA, L.D.“Descobrindo o corpo humano": a prática pedagógica histórico-crítica na educação infantil. RevistaHISTEDBR On-line, Campinas, nº 52, p. 301-320, set2013.

BRASIL. Lei de Diretrizes e Bases da Educação Nacional. Lei número 9394, 20 de dezembro de 1996.

CAMPOS, M. M.; FÜLLGRAF, J.; WIGGERS, V. A Qualidade da Educação Infantil Brasileira: alguns resultados de pesquisa. Cadernos de Pesquisa (Fundação Carlos Chagas. Impresso), v. v.36, p. 87-128, 2006.

CRUZ,S.P.da S.; BATISTA NETO, J. A polivalência no contexto da docência nosanosiniciais da escolarização básica: refletindo sobre experiências de pesquisas. Revista Brasileira de Educação v. $17 \mathrm{n}$. 50 maio-ago. 2012.

DUARTE, N. Vigotski e o "aprender a aprender":críticas às apropriações neoliberais e pós-modernas da teoria vigotskiana. Campinas, SP: Autores Associados, 2011.

GIL, A.C.Métodos e Técnicas de Pesquisa Social. 6 ed. São Paulo: Atlas, 2008.

LAVOURA, T.N. A dialética do singular-universal-particular e o método da pedagogia histórico-crítica. Nuances: estudos sobre Educação, Presidente Prudente-SP, v. 29, n. 2, p.4-18, Mai/Ago, 2018.

LOMBARDI, J.C. Notas sobre a Educação da Infância numa perspectiva marxista. In: MARSIGLIA, A.C.G (Org.). Infância e Pedagogia Histórico- Crítica. Campinas, SP: Autores Associados, 2013.

PASQUALINI, J.C. A perspectiva histórico-dialética da periodização do desenvolvimento infantil. Psicologia em Estudo, Maringá, v. 14, n. 1, p. 31-40, jan/mar. 2009

PASQUALINI, J.C. Periodização do desenvolvimento psíquico à luz da escola de Vigotski: A teoria histórico-cultural do desenvolvimento infantil e suas implicações pedagógicas. In: MARSIGLIA, A.C.G (Org.). Infância e Pedagogia Histórico- Crítica. Campinas, SP: Autores Associados, 2013.

PAULO NETTO, J. Introdução ao estudo do método em Marx. 1 ed. São Paulo: Expressão Popular, 2011.

MALANCHEN, J. Cultura, conhecimento e currículo: contribuições da pedagogia histórico-crítica. Campinas, SP: Autores Associados, 2016.

MANACORDA, M.A. Marx e a formação do homem. Tradução: Newton Ramos-de-Oliveira e Paolo Nosella.Revista HISTEDBR On-line, ISSN: 1676-2584, Campinas, número especial, p. 6-15, abr, 2011.

MARTINS FILHO, A.J; MARTINS FILHO, L.J.“Formação ou conformação?”Crítica a negação ao "ato de ensinar" na educação infantil, 2008.

MARTINS, Lígia Márcia. Fundamentos da Psicologia Histórico-Cultural e da Pedagogia Histórico-Crítica. O Trabalho Pedagógico nas Disciplinas Escolares. 01ed. Campinas: Autores Associados, 2016, v. 01, p. 49-94

ROSSLER, J. H. A educação como aliada da luta revolucionária pela superação da sociedade alienada. In: DUARTE, N. (org.). Crítica ao fetichismo da individualidade. Campinas, SP: Autores Associados, 2004. 
SAVIANI, Educação: do senso comum à consciência filosófica. 19 ed. Campinas, SP: Autores Associados, 2013a.

SAVIANI, D. Pedagogia Histórico-Crítica: primeiras aproximações. 11. ed. Campinas: Autores Associados, 2013b.

SAVIANI, D.; DUARTE, N. A formação humana na perspectiva histórico-ontológica. In: SAVIANI, Dermeval e DUARTE, Newton (orgs.). Pedagogia Histórico- Crítica e luta de classes na educação escolar. Campinas, SP. Autores Associados, 2012 (coleção polêmicas do nosso tempo).

STEMMER, M.R.G. Educação Infantil: gênese e perspectiva. In: ARCE, A \& JACOMELI, M.R.M. (Orgs). Educação Infantil Versus Educação escolar? Entre a (des) escolarização e a precarização do trabalho pedagógico nas salas de aula. Campinas: SP, Autores Associados, 2012.

\section{Como citar este artigo}

MONTEIRO, F. Y. S. Educação Infantil e Pedagogia Histórico- Crítica: apontamentos sobre a educação escolar. Revista Kinesis, Santa Maria, v. 39, p.01-13, 2021.

* O presente trabalho não contou com apoio financeiro de nenhuma natureza para sua realização. 